EPiC Series in Education Science
Volume 1, 2017, Pages 324-331
$\begin{aligned} & \text { AUBEA 2017: Australasian Universities Build- } \\ & \text { ing Education Association Conference 2017 }\end{aligned}$

\title{
Individual Risk Attitudes in Postgraduate Risk Management Education
}

\author{
P. Vaz-Serra ${ }^{1}$, P. Edwards ${ }^{2}$, S. Gao ${ }^{1}$, V. Francis ${ }^{1}$ \\ ${ }^{1}$ University of Melbourne, Melbourne, Australia. \\ ${ }^{2}$ RMIT University, Melbourne, Australia. \\ p.vazserra@unimelb.edu.au, peter.edwards@rmit.edu.au, \\ shang.gao@unimelb.edu.au, vfrancis@unimelb.edu.au
}

\begin{abstract}
Risk management is important for contemporary construction organisations and is a vital constituent of project management education. Before learning about the processes of systematic risk management, construction and project management students need to better understand risk concepts and their own attitudes towards risk. Risk is a psychosocial construct experienced and perceived by individuals. In the Risk in Construction subject offered in the Master of Construction Management programme at the University of Melbourne, students were first invited to respond to a simple questionnaire that measured their own risk attitudes from a task, team and individual risk perspective. This self-knowledge discovery was then applied in their subsequent individual and group assignment work for the subject. The risk profiles were also used in a novel approach to assignment group formation. Students valued the opportunity to explore the alignment between formal project risk management and their own risk attitudes, and used their newly-found understanding in other management-related subjects. Future research will explore cultural and gender influences in these student journeys of self-understanding.
\end{abstract}

\section{Introduction}

Risk is defined as: "the effect of uncertainty upon objectives" (ISO31000, 2009) and nowhere is this more exemplified than with construction projects, since they are conceived, designed, planned, and implemented with many uncertainties associated with the decision-making surrounding the process elements; yet with the intention of fulfilling stated objectives and thus facing risk (Parkin, 1996). While the given definition is neutral, risk may be framed positively or negatively in its effect. In practice, most organisations use risk management proactively to protect objectives from adverse outcomes (threat risk), rather than seeking windfall gain (opportunity risk). While all projects are susceptible to risk, some carry more risk than others. Factors which influence the nature and level of threat risk include: complexity; scope and size (Flyvbjerg et al., 2002); stakeholder inexperience; 
severe time and cost constraints; and technology which is unfamiliar to the user. Such risks are themselves shaped by intrinsic or extrinsic drivers that may be physical, technical, economic, or social in nature (Russell and Nelms, 2007). Edwards et al. (2009) describe systematic project risk management as a proactive process, embracing formal activities that: establish the context (both internal and external); identify, analyse, and respond to risks; monitor and control risks during project execution; and (importantly) capture and manage knowledge of project risks effectively. The decision-making associated with the four essential elements of all projects (tasks, technologies, resources and organisation) provides the basis upon which risk management is implemented and directed (Edwards and Bowen, 2005), but for different project stakeholders these elements, and indeed the objectives sought for the project, will themselves be different. Hence each project stakeholder bears responsibility for managing its own risks, and a single project risk management system common to all stakeholders is impractical, even though there should still be mutual understanding of other stakeholders' risks.

Risk is a psycho-social construct: it arises from an individual's perception of what constitutes a risk and how great the magnitude of that risk might be (Slovic, 2000). Such perceptions are influenced by the cultures in which we exist, through societal norms and attitudes to risk. Furthermore, each of us may have personal risk attitudes that are consonant with, or differ from, our professional risk attitudes. A construction manager may be risk averse personally and professionally; risk seeking privately but risk averse professionally; risk averse privately but risk seeking professionally; or risk seeking in both life dimensions. Unless the two opposing risk attitudes, in both personal and professional dimensions, are known and acknowledged by the individual and by the employer organisation, difficulties may arise for project risk management. However, while individual risk attitudes may change over time, professional risk attitudes are likely to remain relatively stable, and are usually found to be risk averse. Individual risk attitudes translate into organisational risk perspectives through the power of key decision-makers. It is thus possible for one part of a construction organisation to exhibit a different risk attitude compared to another part of the same organisation. However, such dissonance is unlikely to persist since senior management will seek to establish and adhere to uniform risk policies across the organisation. Risk awareness is an important pre-cursor to this (McLucas, 2003).

Thus, while formal risk management should form a substantial topic in the curricula for construction and project management programmes, and be infused in the syllabi for other management-related courses and programmes, it is also vital that students be encouraged to develop deeper insights into their own attitudes to risk. The aim of this paper is to describe how this was attempted in the Master of Construction Management (MCM) programme offered at the University of Melbourne, and how that self-understanding can be used in the formation of groups for subject assignment purposes.

\section{The Construction \& Project Management Program Curricula}

The topic of risk management can be found in many graduate education programmes around the world. It is essential for diplomas and degrees offered in project management, given the nature of projects described earlier and the need for students to acquire knowledge and develop expertise relevant to their careers. In the Master of Construction Management (MCM) program offered at the University of Melbourne, the focus is on the construction industry, especially in terms of projects and people-based activities. The concept of leadership is strongly implemented throughout the program due to the nature of construction management roles, and to enhance the employability of graduates. Within this leadership perspective, however, the emphasis is placed upon team risk management. This reflects similar global initiatives for construction-related degree programmes, developing individual 
capacities but also in a team environment for group and project-based tasks (Olawale, 2015, Arrowsmith et al., 2011).

The MCM at the University of Melbourne (UoM) is normally a three-year degree but, with advanced standing from an undergraduate construction degree, students can achieve the award in two years. Each academic year consists of two twelve-week semesters, and the program offers specialised streams in Project Management, Cost Management and Building. The MCM is essentially a professional degree, for students already holding an undergraduate degree, to prepare leaders for the construction industry. The program uses a case study approach covering the whole life cycle of a construction project from initial concept to delivery of the finished building and on into its operational life. Using the perspectives of client, design team (architects and engineers, quantity surveyors, project managers, etc.), contractors, sub-contractors, finance providers, users, and facilities managers, it prepares students for the realities of professional life. Reflecting the level of involvement of these project stakeholders in graduate programmes in this way is directly related to high levels of employability (Tran, 2015), bringing academia and industry closer together. In a recent study on employability for construction project management degrees, carried out at the Aston University in the UK, 14 skills were identified as critical skills and competencies. Of these, Olawale (2015) found that for project management graduates, employers seek team-work most of all, followed closely by verbal communication, written communication, leadership ability, and flexibility.

The MCM program focuses on five main skills development areas: technical understanding of design and build processes; understanding construction project delivery to meet client expectations (such as costs, time, aesthetic and functional requirements); analysis, evaluation and allocation of risks, and achievement of value; using various methodologies for problem solving and developing capabilities in research, analysis, evaluation and discussion; and developing strong skills, principles and practices in team management and motivating, coaching and leading people. The MCM aims to meet high levels of skills requirements for professional bodies in the construction industry such as the Australian Institute of Building (AIB), Royal Institution of Chartered Surveyors (RICS) and the Australian Institute of Quantity Surveyors (AIQS) [http://study.msd.unimelb.edu.au/programs/masterof-construction-management/overview].

\section{Team-Based Assignment Work}

In the MCM program, many subjects involve group-based assignment work undertaken by small teams or groups of 3 to 5 students. In the past, the formation of such student teams or groups was via personal choice or as directed by the lecturer. Students knew only a few people in their class (with cohorts usually exceeding 60). Generally, they tended to form a group with known friends without any reference other attributes such as personality type, cognitive style or risk perceptions. The assumption, for groups formed in this way, is that all members have about the same level of content specific knowledge, and the sole purpose of the group activity is to apply the knowledge learned throughout the semester simply to complete the assignment often in the most expedient way. Most groups operated in line with a basic model - groups form, they perform a task, and then they disband.

However, this does not accord with the requirements of effective team deployment which is now well documented in business and HRM literature. Miller et al. (1994) note a mix of personality types and cognitive styles across team members may be crucial to team performance. Greenwood (1997) is convinced that an understanding of behaviour towards risk should become fundamental to more effective management, particularly in a team context. Belbin's (2011) team role model and the Margerison and McCann (1990) team management wheel can aid the selection of individuals into teams. Such models are becoming increasingly popular among the building professions (Tennant, 2001). 


\section{A New Approach Postgraduate Risk Management Education}

\subsection{The Subject}

Risk in Construction is a core subject for postgraduate students enrolled in the MCM program at the University of Melbourne. It is offered in the latter part of the degree within both the "Cost Management" and "Project Management" specialisations. Since risk management is regarded as an important pillar to project management in the Project Management Book of Knowledge (PMI, 2013), the subject syllabus aims to achieve the following objectives:

- To build an appreciation of the sources and impacts of risk in construction;

- To provide the generic processes and associated theories, principles and tools to manage risk in construction in a holistic manner;

- To understand qualitative and quantitative methods in analysing risk; and

- To provide generic risk management strategies for use at site and corporate levels in construction.

Organised as an advanced seminar series, the subject exposes students to the various dimensions of risk management from a range of industry stakeholder perspectives. It comprises multiple presentations by guest lecturers, most of whom hold high level positions in industry, who can share different perspectives on risk and their risk management practices. Guest presenters include clients, developers, consultants, designers, contractors, tenants, financiers, and representatives of public authorities.

Subject assessment comprises an individual assignment, a group assignment - including a team presentation, and a two-hour formal written examination (individual). These components are arranged as follows:

- The individual assignment (Assignment \#1) focuses on the identification and evaluation of risk in relation to a hypothetical project from the perspective of a specific project stakeholder.

- The group assignment (Assignment \#2) is a professional report, which involves researching and analysing the risk management structure and impact of the identified risks on a real construction project scenario. Team performance is evaluated through observation of the final project presentation and a group report.

- A two-hour examination focuses on risk management theories and a range of issues relating to risk management in construction covered during the semester.

Formation of the assignment groups was based upon individual risk profiling and described later in this section.

\subsection{Proposition}

Adair in Mullins (1996) notes that risk circumstances can be found in Task, Team, and Individual climates, all of which must be addressed to ensure effective project management. For the Risk in Construction subject, the proposition was formed that assign team members with different risk perceptions in task, team and individual climates would influence team performance. This research is ongoing, and this paper only reports on the method employed to arrive at assignment group formation. There is not yet sufficient data for the performance investigation.

\subsection{Sample}

Students taking the Risk in Construction subject come from various backgrounds. These include engineering, construction management, and architecture. Each semester, about 60-80 students are 
enrolled into the subject, and the risk profiling questionnaire has been administered at the start of the semester for the past three years.

\subsection{Measures}

Greenwood's (1997) questionnaire instrument was adapted as a tool to measure individual selfperceived behaviours towards risk in Task, Team and Individual climates (see Table 1). In her study, perception about behaviour towards risk was captured with six scenario sections.

\begin{tabular}{ll}
\hline Behaviour towards risks & Scenarios \\
\hline Tasks & Section 1 - "When taking on new work, I believe...." \\
& Section 2 - "How do you view failure" \\
\hline Team & Section 3 - "When leading my team, I..." \\
& Section 4 - "As a leader, I..." \\
\hline Individual & Section 5 - "I Perceive myself as..." \\
& Section 6 - "In a changing environment I value..." \\
\hline
\end{tabular}

Table 1: Climates and scenarios of the risk perception instrument (Source: (Greenwood, 1997))

Each scenario has eight pre-set responses describing behaviours graded from low to high perceived risk. Respondents must select one or more responses, and allocate a total of 10 points among the statements for each scenario, thereby weighting their self-perceived behaviour for each scenario. The points in each climate are totalled and further weighted to accentuate the participant's overall low to high perceived risk-taking behaviour. The relevance of Greenwood's (1997) measurement tool is shown in Figure 1.

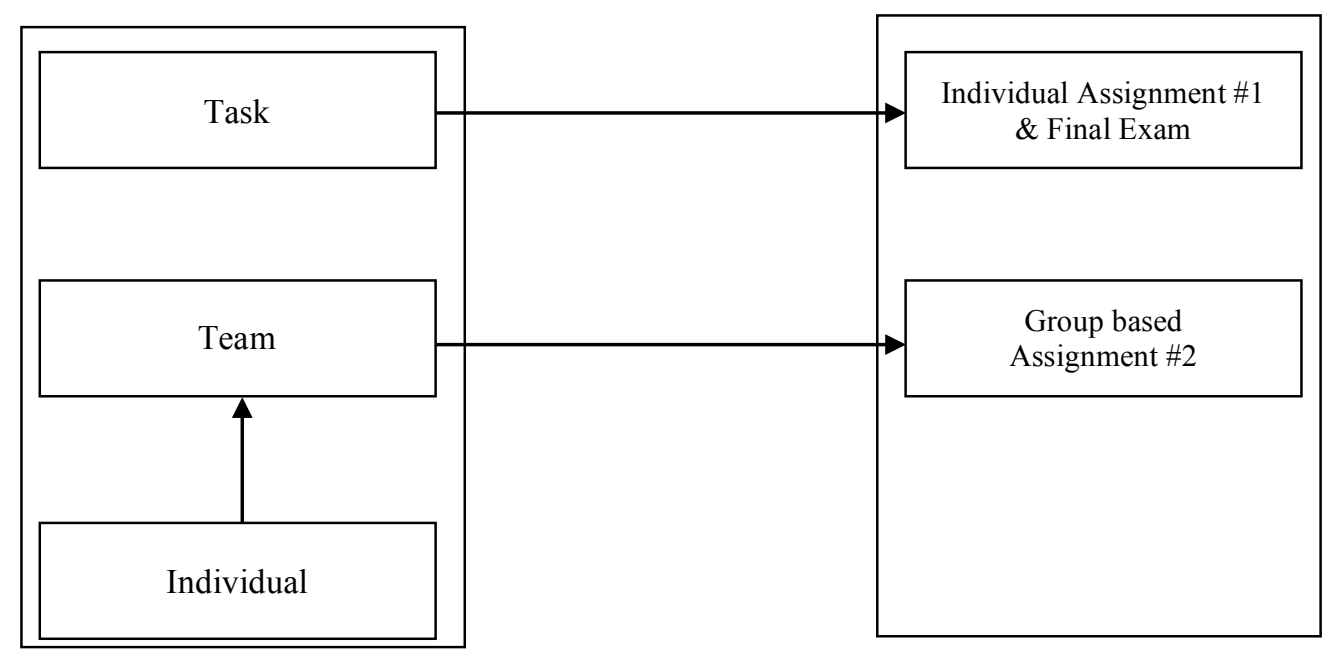

Figure 1: Relevance of the Greenwood (1997) risk profiling instrument to the MCM course assessment requirements

Table 2 shows an example of "Team" climate from Greenwood's instrument which reflects the relevance of the measurement tool study to the discipline of project management. 


\begin{tabular}{|c|c|c|}
\hline Section 3 & When leading my team, I... & Keywords \\
\hline $\mathrm{a}$ & Always provide specific instructions & Specific instructions \\
\hline b & Make an effort to explain decisions & Explain decisions \\
\hline $\mathrm{c}$ & Turn over responsibility for decisions & Responsibility \\
\hline $\mathrm{d}$ & Share ideas & Share ideas \\
\hline $\mathrm{e}$ & Closely supervise performance & Supervise \\
\hline $\mathrm{f}$ & Provide opportunity for clarification & Clarification \\
\hline $\mathrm{g}$ & Work with my team to make decisions & Work with team \\
\hline $\mathrm{h}$ & Turn over responsibility for implementation & $\begin{array}{l}\text { Responsibility for } \\
\text { implementation }\end{array}$ \\
\hline Section 4 & As a leader, I... & \\
\hline a & Like to broadcast the successes of my team & $\begin{array}{l}\text { To broadcast the } \\
\text { successes }\end{array}$ \\
\hline b & Trust information passed down from senior managers & Trust information \\
\hline $\mathrm{c}$ & Encourage criticism of my leadership & Criticism \\
\hline $\mathrm{d}$ & Am likely to check information given to me by my peers & \\
\hline $\mathrm{e}$ & Require my team to keep in touch & Keep in touch \\
\hline $\mathrm{f}$ & Like to communicate my team's failures & Communicate failure \\
\hline $\mathrm{g}$ & Am comfortable to delegate my leadership role & Delegate \\
\hline $\mathrm{h}$ & Only share with my team the information they need to know & Share \\
\hline
\end{tabular}

Table 2: Risk profile measurement tool: “Team” example (Source: Adapted from Greenwood (1997))

All the statements and keywords were considered relevant and important to project management. Students assessed the relative personal importance of each statement by allocating scores to each one, to arrive at a total of 10 points for each section. It is acceptable for some statements to be given a zero score, or even one to get all ten points.

\subsection{Outcomes}

The quality of students' assignments relies on the effective participation of all team members. As a general rule, groups of four members tend to work well, and at UoM this group size is normally adopted as a maximum. The method adopted for team formation in the assignment work for the Risk in Construction subject used the following sequence:

1. At the first class, printed copies of the profiling instrument are distributed. After the subject co-ordinator has explained its purpose, the attending students complete and hand in their calculated profiles. Absentee students are followed up via email to complete their risk profile.

2. Once students have completed the questionnaire and scored calculated, each student then knows her/his own self-perceived attitudes towards risk in all three situations or climates,

3. The "Team" climate scores for the whole student cohort are then ranked from low to high. Four group "bands" are then determined. The highest $25 \%$ are considered as risk-averse, the bottom $25 \%$ as risk-takers; and the remaining quartiles allocated in the mid-ranges.

4. Students in each band then have some choice in the group formation process in that each must choose (or negotiate with) one team mate from each of the other three bands.

5. Eventually each assignment group is formed and ideally comprises at least one student from each risk profile band. The groups are then formally registered, and further changes to group composition can only be made with the approval of the subject co-ordinator.

6. The co-ordinator closely monitors assignment progress and final assignment results for each group.

7. The students are required to organise and conduct group meetings to progress their assignment. 
By undertaking this group formation process it has been found that students in the subject not only gain deeper understanding of their own attitudes towards risk, but also experience working alongside others, with different risk attitudes, in a team environment to fulfil mutually shared assignment work objectives. This process was undertaken during semester classes and no detailed results are yet available. However, data will be collected in future years and a more systematic analysis of the results will become available for consideration. The selection for the composition of the teams for the group assignment will be done by different levels of team risks. The results will be correlated with performance in the individual assignment, the group assignment, and with the final examination. An interview with each team leader of the group assignment, at the end of the semester, is intended, based on the minutes of meetings of the group and measures to evaluate the performance of the team.

\section{Discussion and Conclusions}

Risk is pervasive in construction projects, and those who are involved in them must know how to deal with it. Projects are team-based endeavours and thus reflect the influences of multiple individual risk profiles in the decision-making processes that all projects go through. Individual risk attitudes turn into organisational risk perspectives through these processes. For students of project management, it is important for them not only to learn about risk management, but also to understand how their own attitudes towards risk might affect their individual, as well as team, performance. We have described how this is being done with students in a construction management master's degree program that also inculcates leadership and communication skills. We have proposed and implemented a new approach for teaching risk management that draws students through a selfperceived assessment of task, team, and individual risk climate evaluations. The resulting risk profiles are then used to create more balanced student groups for assignment purposes. The process aims to more closely align the recommendations of research in business and HRM with the inherent nature of project management and the stakeholder structure of projects.

Students have responded well to this approach. They value discovering their own risk profiles in various settings, and are interested in seeing how this impacts on their contribution to assignment work in groups where fellow team members have significantly different risk profiles. This first implementation of the approach has been qualitative, based on individual feedback of the team leaders of each group assignment. However, we have clearly identified that team skills to address individual risks are essential to the performance of the team results, and the importance of this to be included in postgraduate programs. Some students have then used the same approach in other subjects. Further research is planned to assess the impact of this novel approach, through a larger data-set and additional profiling factors (gender, culture, etc.) on individual and team performance.

\section{References}

Arrowsmith, C., Bagoly-Simó, P., Finchum, A., Oda, K., \& Pawson, E. (2011). Student employability and its implications for geography curricula and learning practices. Journal of Geography in Higher Education, 35, 365-377.

Belbin, R. M. (2011). Management teams: why they succeed or fail. Human Resource Management International Digest, 19.

Edwards, P. J., \& Bowen, P. A. (2005). Risk management in project organisations. Sydney : UNSW Press. 
Edwards, P. J., Bowen, P. A., Hardcastle, C., \& Stewart, P. J. (2009). Identifying and communicating project stakeholder risks. Paper presented at the Construction Research Congress 2009: Building a Sustainable Future. ASCE. Seattle, Washington, USA. 5-7 April. 776-785.

Flyvbjerg, B., Rothengatter, W., \& Bruzelius, N. (2002). Megaprojects and risk: an anatomy of ambition: New York : Cambridge University Press, 2003.

Greenwood, M. (1997). Discovering and individual's risk behaviour profile. Paper presented at the Proceedings of the 13th Annual ARCOM Conference, Kings College Cambridge.

ISO31000. (2009). Risk management - Principles and guidelines. Standards Australia. Sydney. Books.

Margerison, C. J., \& McCann, D. (1990). Team management: Practical new approaches. Mercury

McLucas, A. C. (2003). Decision making: risk management, systems thinking and situation awareness. Argos Press P/L.

Miller, C., English National Board for Nursing, M., Health Visiting, L., \& et al. (1994). Learning Styles and Facilitating Reflection. Researching Professional Education. Research Reports Series (0946810-55-9).

Mullins, L. J. (1996). Management and organizational Behavior Great Britain. In: Pitman Publishing.

Olawale, Y. (2015). The employability skills provision within a construction project management degree programme. 31st Annual ARCOM conference, 7-9 September 2015, Lincoln, UK.

Parkin, J. (1996). Management decisions for engineers: London : T. Telford, 1996.

PMI. (2013). The Project Management Book of Knowledge (PMBOK). Newtown Square, Pennsylvania, USA: Project Management Institute.

Russell, A. D., \& Nelms, C. E. (2007). The application of information technology to support the elicitation of expert judgement in project risk management. In: Scientific Committee, 1355.

Slovic, P. (2000). The perception of risk London. UK: Earthscan.

Tennant, S 2001, Belbin and the Formation of Construction Project Teams. in CIB World Building Congress: Performance in Product and Practice 2nd-6th April 2001, Wellington, New Zealand. CIB World Building Congress.

Tran, T. T. (2015). Is graduate employability the 'whole-of-higher-education-issue'?. Journal of Education and Work, 28, 207-227. 